\title{
Comparison between Bilateral C2 Pedicle Screwing and Unilateral C2 Pedicle Screwing, Combined with Contralateral C2 Laminar Screwing, for Atlantoaxial Posterior Fixation
}

\author{
Naohisa Miyakoshi ${ }^{1}$, Michio Hongo ${ }^{1}$, Takashi Kobayashi ${ }^{2}$, Tetsuya Suzuki ${ }^{3}$ Eiji Abe $^{2}$, Yoichi Shimada $^{1}$ \\ ${ }^{1}$ Department of Orthopedic Surgery, Akita University Graduate School of Medicine, Akita, Japan \\ ${ }^{2}$ Department of Orthopedic Surgery, Akita Kumiai General Hospital, Akita, Japan \\ ${ }^{3}$ Department of Orthopedic Surgery, Akita Red Cross Hospital, Akita, Japan
}

\section{Study Design: A retrospective study.}

Purpose: To compare clinical and radiological outcomes between bilateral C2 pedicle screwing (C2PS) and unilateral C2PS, combined with contralateral C2 laminar screwing (LS), for posterior atlantoaxial fixation.

Overview of Literature: Posterior fixation with C1 lateral mass screwing (C1LMS) and C2PS (C1LMS-C2PS method) is an accepted procedure for rigid atlantoaxial stabilization. However, conventional bilateral C2PS is not always allowed in this method due to anatomical variations of C2 pedicles and/or asymmetry of the vertebral artery. Although unilateral C2PS plus contralateral LS (C2PS+LS) is an alternative in such cases, the efficacy of this procedure has not been evaluated in controlled studies (i.e., with bilateral C2PS as a control).

Methods: Clinical and radiological records of patients who underwent the C1LMS-C2PS method, using unilateral C2PS+LS (n=9), and those treated using conventional bilateral C2PS $(n=10)$ were compared, with a minimum two years follow-up.

Results: Postoperative complications related to the unilateral C2PS+LS technique included one case of spontaneous spinous process fracture of $\mathrm{C2}$. A C1 anterior arch fracture occurred after a fall in one patient, who underwent bilateral C2PS and C1 laminectomy. No significant differences were seen between the groups in reduction of neck pain after surgery or improvement of neurological status, as evaluated using the Japanese Orthopaedic Association score. A delayed union occurred in one patient each of the groups, with the final fusion rate being $100 \%$ in both groups.

Conclusions: Clinical and radiological outcomes of unilateral C2PS+LS were comparable with those of the bilateral C2PS fixation technique for the C1LMS-C2PS method.

Keywords: Cervical spine; Atlantoaxial instability; Laminar screw; Pedicle screw

\section{Introduction}

Posterior fixation with C1 lateral mass screwing (LMS) and $\mathrm{C} 2$ pedicle screwing (PS) (C1LMS-C2PS method), also known as the Goel-Harms technique, was clinically introduced by Goel and Laheri [1] in 1994. Harms and

Received Dec 6, 2013; Revised Dec 31, 2013; Accepted Jan 16, 2014

Corresponding author: Naohisa Miyakoshi

Department of Orthopedic Surgery, Akita University Graduate School of Medicine,

1-1-1 Hondo, Akita 010-8543, Japan

Tel: +81-18-884-6148, Fax: +81-18-836-2617, E-mail: miyakosh@doc.med.akita-u.ac.jp 
Melcher [2] described a modified technique in 2001, using polyaxial screws and rods, to minimize the risk of injury to the vertebral artery (VA), allow intraoperative reduction of the atlantoaxial complex, and achieve a good fusion rate. However, C2PS also carries a potential risk of VA injury; and such injuries have been reported $[3,4]$.

As an alternative to C2PS, Wright [5] introduced the use of bilateral laminar screws (LSs) crossing the C2, to completely avoid risk to the VA. C2LS has become increasingly used as an alternative to C2PS $[3,6]$. Successful results of $\mathrm{C} 1-\mathrm{C} 2$ fixation using crossing C2LSs have been reported $[3,6]$. However, cadaveric studies simulating traumatic instability (odontoid fracture model) have demonstrated inferior stability of bilateral C2LS fixation, compared with bilateral C2PS fixation in lateral bending and axial rotation $[7,8]$. In addition, this technique depends on the integrity of the C2 lamina, and thus cannot completely replace the transarticular screw or C2PS techniques [9].

Another modification is a hybrid of the unilateral C2PS and contralateral C2LS (unilateral C2PS+LS). This modification is considered to be more rigid than the bilateral C2LS method and safer than the bilateral C2PS method. We therefore adopted this modification for cases in which bilateral C2PS is not allowed due to asymmetry of the VAs, including unilateral occlusion of a VA and/or pedicle deformity of C2. To the best of our knowledge, no comparative studies of this modified hybrid technique have been reported. In this study, the clinical and radiological records of patients with atlantoaxial lesions, who underwent unilateral C2PS+LS technique, were compared with those of patients treated with the conventional bilateral C2PS technique in the C1LMS-C2PS method.

\section{Materials and Methods}

\section{Patients}

A total of thirty-eight consecutive patients underwent the C1LMS-C2PS method for atlantoaxial lesions at our institution, with a follow-up of at least two years. Among these patients, in order to compare patients only in terms of the technique for $\mathrm{C} 2$ fixation (bilateral C2PS vs. unilateral C2PS+LS) for atlantoaxial posterior fixation, the following patients were excluded from the study: 1) twelve patients who underwent combined surgery for other spinal lesions (i.e., laminoplasty or additional subaxial spinal fusion for complex cervical deformity); and 2) seven patients who underwent C1LMS placed via the posterior arch into the lateral mass (Tan's technique [10]), because different screw placement techniques for $\mathrm{C} 1$ might also affect the results.

The remaining nineteen patients ( 6 men, 13 women), with a mean age of 65.4 years (range, 35-84 years), who underwent isolated atlantoaxial posterior spinal fusion with bilateral C1LMS with direct insertion into the lateral mass (conventional Goel-Harms technique), were evaluated in this study. The cause of atlantoaxial instability was rheumatoid arthritis in 8 patients, trauma in 4 patients, idiopathic in 3 patients, idiopathic combined with retroodontoid pseudotumor in 2 patients, os odontoideum in 1 patient, and achondroplasia in 1 patient. Patients were divided into two groups according to the $\mathrm{C} 2$ screwing technique: bilateral C2PS group $(\mathrm{n}=10)$ and unilateral C2PS+LS group $(\mathrm{n}=9)$.

Prior to surgery, in addition to neutral and flexionextension lateral radiographs and magnetic resonance imaging (MRI), all patients underwent computed tomography (CT) with multiplanar reconstruction to evaluate the anatomy of $\mathrm{C} 2$ pedicles and laminae, as well as threedimensional (3D)-CT angiography to identify anatomical variations of the VA in atlantoaxial lesions.

\section{Surgical procedures}

Patients were placed in the prone position with the head and cervical spine maintained in the neutral position, using a Mayfield head-holder. A standard exposure was performed. Care was taken to preserve the attachment of the semispinalis cervicis to the caudal aspect of the C2 spinous process. In cases requiring $\mathrm{C} 1$ decompression, C1 laminectomy was completed before screwing.

We adopted the entry point for $\mathrm{C} 1$ screws as suggested by Hong et al. [11]; that is, at the intersection of the inferior border of the posterior $\mathrm{C} 1$ arch and the midpoint of the $\mathrm{C} 1$ lateral mass. However, caudal projections (protuberances) of the $\mathrm{C} 1$ arch corresponding to the entry point were drilled to allow for a less cranially-tilted screw trajectory. With the C2 nerve gently retracted caudally, a high-speed burr was used to create an entry hole 2-3 $\mathrm{mm}$ in depth to prevent slippage of the drill bit, followed by gentle drilling and tapping. Then polyaxial screws of 
the appropriate length (3.5-mm diameter, Vertex Max; Medtronic Sofamor Danek, Memphis, TN, USA) were inserted into the lateral mass bilaterally under lateral fluoroscopic guidance. Although bicortical C1LMS has been recommended by some [2] to obtain better stability, we usually use unicortical screws to prevent screw-tip injuries to the internal carotid artery [12] and hypoglossal nerve [13]. However, the longest possible unicortical screws were inserted.

For C2PS, medial and superior borders of the C2 pedicle (pars interarticularis) were used as reference planes to direct screw placement into the pedicle. These planes are basically parallel to the pedicle axis in lateral and superior projections and represent the real individual angulation of the $\mathrm{C} 2$ pedicle [14]. Our entry point for C2PS was determined with reference to preoperative 3D$\mathrm{CT}$ in $30^{\circ}$ oblique view, where the screw trajectory could be as close as possible to the upper and medial cortex of the pedicle to prevent VA injury. Usually, the entry point was located at the intersection of the most curved portion of the lamina and the extension line of the upper edge of the pedicle. Once the medial and upper borders of the pedicle were palpated with a Penfield dissector to confirm the anatomical shape of the pedicle, the entry point was marked with a high-speed burr. The pilot hole was created gently with a probe, directed as much cephalad and inward as possible. Confirmation of the pedicle cavity with a pedicle sounder was performed before tapping. The unicortical C2 pedicle screw (diameter, $3.5 \mathrm{~mm}$; the longest possible) was inserted under lateral fluoroscopic guidance, aiming toward the anterior edge of the $\mathrm{C} 1-\mathrm{C} 2$ joint.

C2LS was selected for the side of the dominant VA if the patient showed asymmetrical VAs and/or the $\mathrm{C} 2$ pedicle was $<4 \mathrm{~mm}$ in diameter. For C2LS, a high-speed burr was used to open a small cortical window at the junction of the $\mathrm{C} 2$ spinous process and lamina [5]. After probing and tapping, an appropriate-length 3.5-mm-diameter screw was inserted.

After connecting rods between the $\mathrm{C} 1$ and $\mathrm{C} 2$ screws, monocortical, morsellized, autologous iliac crest bone harvested from the right posterior iliac crest was grafted between the decorticated posterior surfaces of $\mathrm{C} 1$ and C2 and wedged underneath the rods. C1-C2 facet decortication was also undertaken in cases of $\mathrm{C} 1$ laminectomy, prior to rod and screw connection. The morsellized bone graft was then packed around the remaining exposed bone surfaces.

All patients were routinely immobilized with a cervical collar for twelve weeks. Operation time, blood loss, and complications during and after surgery were compared between the bilateral C2PS group and unilateral C2PS+LS group.

\section{Clinical assessment}

Existence of neck pain before and after surgery was determined in interviews. Evaluations for neck pain relief were rated as excellent, good, fair, or poor [15]. The result was considered to be excellent if the patient achieved near-complete relief of pain in the neck. A good result indicated occasional discomfort in the neck, necessitating occasional non-narcotic medication. Patients with a good result achieved a significant improvement compared with the preoperative condition. A fair result was defined as intermittent discomfort in the neck and improvement compared with the preoperative condition. Patients who had poor results showed marked discomfort in the neck, necessitating non-narcotic medication.

For the assessment of neurological status, we used the scoring system for cervical myelopathy proposed by the Japanese Orthopaedic Association (JOA) [16]. This JOA scoring system consists of seven categories: motor function of the fingers $(0-4)$, shoulder and elbow ( -2 to 0$)$, and lower extremity $(0-4)$; sensory function of upper extremity $(0-2)$, trunk $(0-2)$, and lower extremity $(0-2)$; and function of the bladder (0-3). This system evaluates the severity of myelopathy by assessing scores based on the degree of dysfunction in each category. The full score is 17 , with higher scores indicating higher levels of neurological function.

\section{Radiological assessment}

On lateral radiographs of the cervical spine, atlanto-dental interval (ADI) in the flexion position and atlanto-axial angle (C1-C2 angle) in the neutral position were measured, before and after surgery and at the final follow-up. The $\mathrm{C} 1-\mathrm{C} 2$ angle was defined as the angle between an extended line connecting the centers of the anterior and posterior arches of the $\mathrm{C} 1$ and an extended line connecting the inferior endplate of the $\mathrm{C} 2$.

Fusion rates were evaluated with CT obtained every six months. Solid fusion was defined by bony trabecular con- 
Table 1. Background data of patients who underwent C1-C2 posterior fixation for atlantoaxial lesions

\begin{tabular}{|c|c|c|c|}
\hline Characteristic & Bilateral C2PS $(n=10)$ & Unilateral C2PS+LS (n=9) & $p$-value \\
\hline Age (yr) & $67.7 \pm 8.7$ & $62.9 \pm 14.9$ & 0.397 \\
\hline Sex (male:female) & $4: 6$ & $2: 7$ & 0.764 \\
\hline Type of instability & & & 0.991 \\
\hline Rheumatoid arthritis & 4 & 4 & \\
\hline Post-traumatic & 2 & 2 & \\
\hline Idiopathic & 2 & 1 & \\
\hline Retro-odontoid pseudotumor & 1 & 1 & \\
\hline Others & 1 (os odontoideum) & 1 (achondroplasia) & \\
\hline \multicolumn{4}{|l|}{ Symptoms (n [\%]) } \\
\hline Neck pain & $8 / 10(80.0)$ & $6 / 9(66.7)$ & 0.510 \\
\hline Neurological deficits & $10 / 10(100.0)$ & $9 / 9(100.0)$ & 1.000 \\
\hline \multicolumn{4}{|l|}{$\operatorname{BMD}\left(\mathrm{g} / \mathrm{cm}^{2}\right)^{\mathrm{a})}$} \\
\hline Lumbar spine (L2-L4) & $0.859 \pm 0.077$ & $0.985 \pm 0.180$ & 0.160 \\
\hline Total hip & $0.730 \pm 0.162$ & $0.878 \pm 0.215$ & 0.247 \\
\hline
\end{tabular}

Values are presented as mean \pm standard deviation or number of patients.

No significant differences in any parameters were seen between groups.

PS, pedicle screwing; LS, laminar screwing; BMD, bone mineral density.

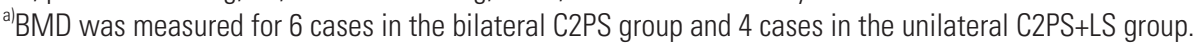

nectivity in CT. Non-union was determined if a visible gap still existed on CT at final follow-up. Delayed union was defined if union was not seen on CT at six months, but was apparent at final follow-up.

\section{Bone mineral density}

Because bone fragility may affect radiological outcomes, preoperative bone mineral density (BMDs) of the lumbar spine (L2-L4) and total hip were measured using dualenergy X-ray absorptiometry (QDR Discovery, Hologic, Bedford, MA, USA), in cases of suspected osteoporosis.

\section{Statistical analysis}

All data were analyzed using a statistical software package (StatView, SAS Institute, Cary, NC, USA). For continuous variables, data were expressed as mean \pm standard deviation. Statistical differences between groups were compared using the $t$-test (paired or unpaired) or MannWhitney $\mathrm{U}$ test, as appropriate. The chi-square test was used for categorical variables. Probability values less than 0.05 were considered statistically significant.

\section{Results}

\section{Comparison of background data}

A summary of background data for study subjects in the two groups is provided in Table 1. No significant differences were seen between groups regarding age, sex, type of instability, and preoperative symptoms. Combined with $\mathrm{C} 1-\mathrm{C} 2$ posterior instrumented fusion, two patients in the bilateral C2PS group and two patients in the unilateral C2PS+LS group required C1 laminectomy for retro-odontoid pseudotumor or atlas hypoplasia. BMDs of the lumbar spine and total hip in cases with suspected osteoporosis (six cases in the bilateral C2PS group; and four cases in the unilateral C2PS+LS group) showed no significant differences between groups.

\section{Operative invasiveness and complications}

Surgery tended to last longer in the bilateral C2PS group $(208.8 \pm 38.5 \mathrm{~min})$ than in the unilateral C2PS+LS group $(172 \pm 53.1 \mathrm{~min})$, but no significant difference was seen ( $p=0.103$ ). Mean blood loss during surgery also tended to be larger in the bilateral C2PS group $(265.6 \pm 298.6 \mathrm{~mL})$ 
than in the unilateral C2PS+LS group $(128.7 \pm 124.3 \mathrm{~mL})$, but again with no significant difference $(p=0.219)$. During surgery, no cases of iatrogenic neurological deficit or VA injury were observed. Excessive bleeding from the epidural venous plexus that could be controlled was encountered in some cases in both groups, when exposing the entry point for C1LMS. No cases of apparent surgicalsite infection or instrumentation failure were observed in either group.

Postoperative fracture at the $\mathrm{C} 1-\mathrm{C} 2$ level occurred in one patient from each group. One patient with achondroplasia (a 48-year-old woman) in the unilateral C2PS+LS group sustained spontaneous $\mathrm{C} 2$ spinous process fracture three days postoperatively (Fig. 1). Because
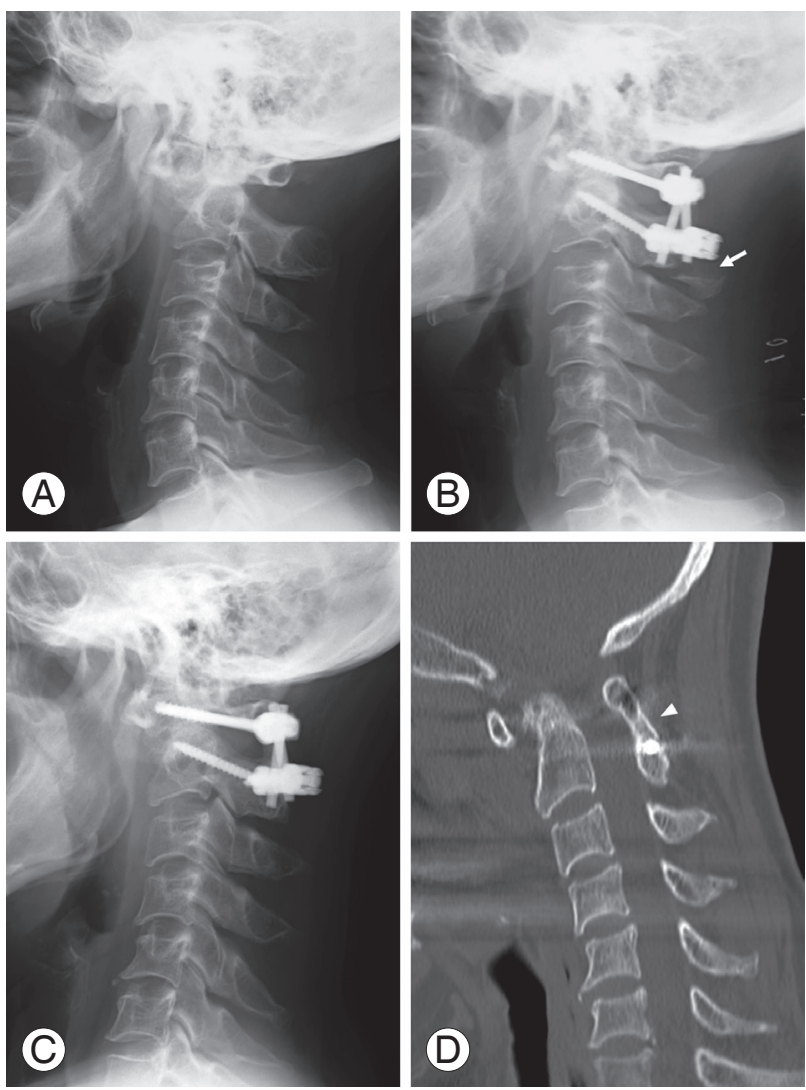

Fig. 1. A 48-year-old woman with atlantoaxial instability and achondroplasia underwent posterior C1-C2 fixation with bone grafting, using bilateral C1 lateral mass screws, unilateral C2 pedicle screw, and contralateral C2 laminar screw. (A) Preoperative lateral X-ray in the neutral position, revealing severe atlantoaxial subluxation. (B) Postoperative lateral $\mathrm{X}$-ray obtained 3 days after surgery, showing good reduction of subluxation by instrumentation and spinous process fracture of C2 (arrow). (C) Postoperative lateral X-ray obtained 3 years after surgery, showing slight correction loss. (D) Computed tomography in sagittal orientation obtained 3.5 years after surgery, showing solid bone union (arrowhead). the patient experienced severe neck pain, the wound was opened again to confirm whether the C2LS was loosened or not. Intraoperatively, C2LS was not loosened, and no additional instrumentation was performed. The fractured C2 spinous process was removed, and the posterior cervical musculature was gently repaired. Cervical orthosis was applied for six months for this patient. Follow-up X-rays and CTs showed a slight loss of correction and delayed union, but solid bone union was finally obtained.

The other fracture case involved an 84-year-old blind man in the bilateral C2PS group. This patient also underwent $\mathrm{C} 1$ laminectomy for retro-odontoid pseudotumor. He sustained $\mathrm{C} 1$ anterior arch fracture four months after surgery from a fall in his house (Fig. 2). The patient was treated conservatively with a cervical collar for twelve months postoperatively. Bone union was delayed, but was finally obtained, and the retro-odontoid pseudotumor disappeared.

\section{Clinical outcomes}

Follow-up rate was $100 \%$ in both groups. Follow-up periods in both groups were comparable, with no significant differences seen between groups (Table 2). No patient showed worsening symptoms after surgery. Clinical outcome, assessed according to relief of neck pain at final follow-up, was excellent or good in $100 \%$ of patients in both groups. The aforementioned two patients who experienced postoperative fracture (one patient in each group) achieved a rating of good pain relief at final follow-up.

Neurological status evaluated with JOA score was significantly improved after surgery in both groups. Recovery rates in both groups were comparable, and no significant difference was apparent between groups.

\section{Radiological outcomes}

Satisfactory positions of screws were noted on X-rays in all patients. Postoperative CT confirmed all screw threads of $\mathrm{C} 1$ and $\mathrm{C} 2$ screws remained completely within the bone for all patients in both groups. No instability was seen on postoperative flexion-extension X-rays in any patient in either group. No cases of instrumentation failure were observed in either group at final follow-up. In both groups, ADI significantly decreased and $\mathrm{C} 1-\mathrm{C} 2$ angle 

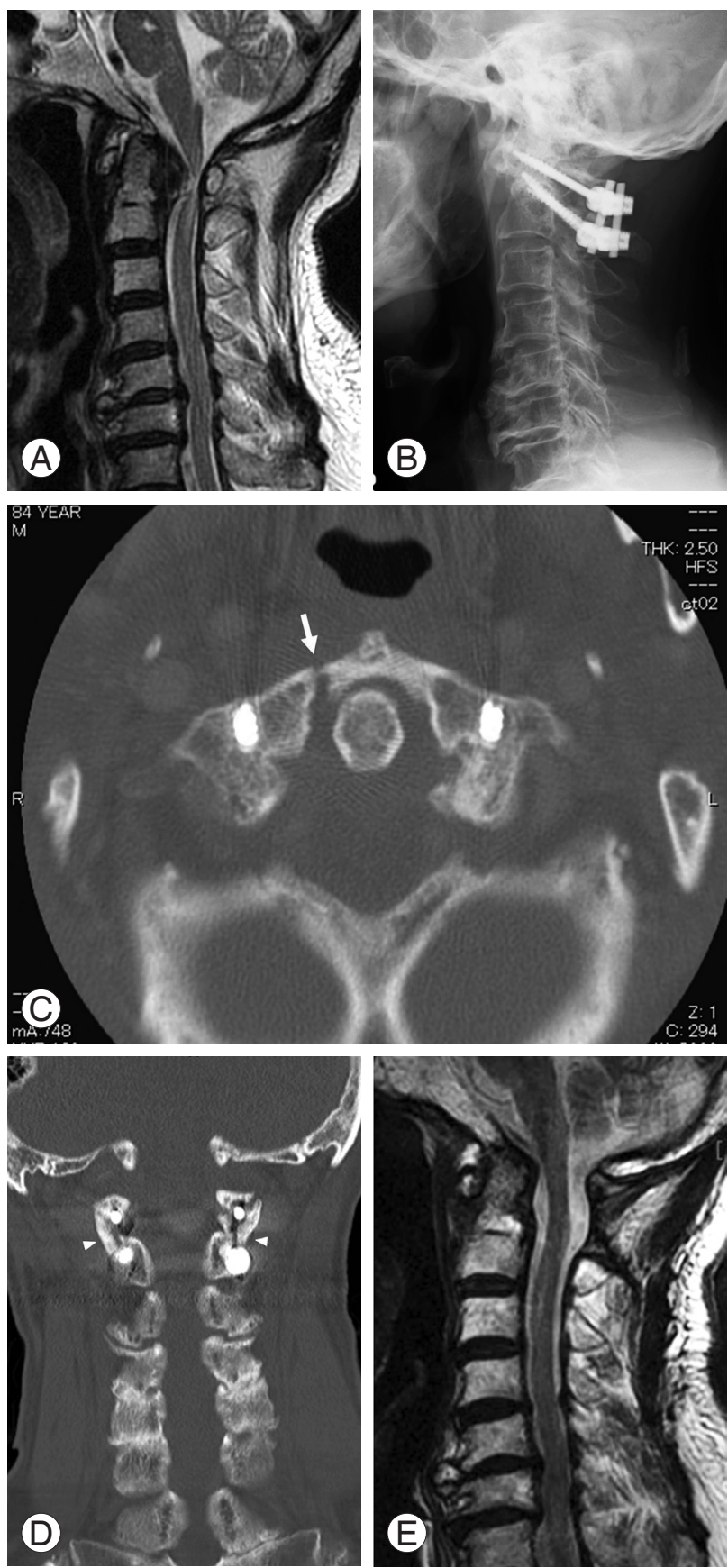

Fig. 2. An 84-year-old man with atlantoaxial instability and retroodontoid pseudotumor underwent C1 laminectomy and posterior C1C2 fixation with bone grafting, using bilateral $\mathrm{C} 1$ lateral mass screws and bilateral $\mathrm{C} 2$ pedicle screws. (A) Preoperative sagittal T2-weighted magnetic resonance imaging (MRI), showing severe spinal cord compression by a retro-odontoid pseudotumor. (B) Postoperative lateral $\mathrm{X}$-ray taken 1 month after surgery, showing good placement of screws. (C) Computed tomography (CT) in axial orientation obtained after sustaining a fall on the floor (4 months after surgery), showing C1 anterior arch fracture (arrow). (D) CT in coronal orientation obtained 2 years after surgery, showing bone union of the C1-C2 joint (arrowheads). (E) Postoperative sagittal T2-weighted MRI obtained 2.5 years after surgery, showing disappearance of the retro-odontoid pseudotumor. significantly increased after surgery; and they were sustained at the final follow-up (Table 3). There were no statistical differences between groups in reduction of ADI, restoration of $\mathrm{C} 1-\mathrm{C} 2$ angle, and the loss of correction.

The aforementioned case with postoperative $\mathrm{C} 2 \mathrm{spi}$ nous process fracture in the unilateral C2PS+LS group and with postoperative $\mathrm{C} 1$ anterior arch fracture in the bilateral C2PS group showed delayed union. However, bone unions of these patients were confirmed on followup CT. Final fusion rates evaluated with CT were thus $100 \%$ for both groups.

\section{Discussion}

It has been shown that posterior wiring alone does not provide adequate stability [15]. As such, atlantoaxial transarticular screw fixation and the C1LMS-C2PS method are considered to be the most effective techniques. However, these techniques are technically demanding and pose risk of injury to the VA. Vergara et al. [4] recently compared the pros and cons of transarticular screw fixation $(n=76)$ and the C1LMS-C2PS method $(n=47)$. They reported that although fusion rates were comparable, the rate of intraoperative VA injury was significantly higher in the transarticular screw fixation group (9.2\%) than in the C1LMS-CSPS group (2.1\%; $p \leq 0.05)$. In their study, a death due to bilateral VA injury was also included in the transarticular fixation group [4]. As a result, the C1LMSC2PS method is thought to carry a lower risk of injury to the VA than transarticular screw fixation. However, a risk of injury to the VA still exists for C2PS. Variable pedicle size, angle and location of the foramen transversarium and either asymmetry or hypoplasia of the VA can make placement of this screw difficult, with a high risk of injuring the adjacent VA $[14,17]$. A study using 3D-CT to evaluate the trajectories of atlantoaxial transarticular screws and C2PS in a total of 62 patients with cervical lesions showed that C2PS placement has nearly the same anatomic risk of VA injury as transarticular screw placement [18].

As an alternative to C2PS, C2LS has been introduced [5]. One major advantage of this technique is the complete removal of risk to the VA with C2 screw placement, as the screws remain in the posterior elements [5]. Although successful results of $\mathrm{C} 1-\mathrm{C} 2$ fixation using crossing C2LSs have been reported $[3,6]$, these studies have not included controls. In addition, crossing C2LSs cannot 
Table 2. Clinical outcomes of C1-C2 posterior fixation for atlantoaxial lesions

\begin{tabular}{|c|c|c|c|}
\hline Characteristic & Bilateral C2PS $(n=10)$ & Unilateral C2PS+LS (n=9) & $p$-value \\
\hline Follow-up period (mo) & $46.3 \pm 18.1$ & $46.2 \pm 14.8$ & 0.992 \\
\hline Relief of neck pain & & & 0.796 \\
\hline Excellent & 6 & 4 & \\
\hline Good & 2 & 2 & \\
\hline Fair & 0 & 0 & \\
\hline Poor & 0 & 0 & \\
\hline \multicolumn{4}{|l|}{ JOA score } \\
\hline Preoperative & $10.0 \pm 3.3$ & $10.5 \pm 4.1$ & 0.753 \\
\hline Follow-up & $13.8 \pm 2.0^{\mathrm{a})}$ & $13.6 \pm 3.2^{\text {a) }}$ & 0.879 \\
\hline Recovery rate (\%) & $58.3 \pm 29.3$ & $54.5 \pm 34.8$ & 0.798 \\
\hline
\end{tabular}

Values are presented as mean \pm standard deviation or number of patients.

No significant differences in any parameters were seen between groups.

PS, pedicle screwing; LS, laminar screwing; JOA, Japanese Orthopaedic Association.

${ }^{\text {a) }} p<0.05$ vs. preoperative JOA score.

Table 3. Radiological outcomes of C1-C2 posterior fixation for atlantoaxial lesions

\begin{tabular}{|c|c|c|c|}
\hline Characteristic & Bilateral C2PS (n=10) & Unilateral C2PS+LS (n=9) & $p$-value \\
\hline \multicolumn{4}{|c|}{ Atlanto-dental interval (mm) } \\
\hline Preoperative & $6.2 \pm 2.7$ & $6.2 \pm 2.9$ & 0.980 \\
\hline Postoperative & $1.8 \pm 0.3^{\mathrm{a})}$ & $2.0 \pm 1.0^{\mathrm{a})}$ & 0.560 \\
\hline Follow-up & $1.9 \pm 0.4^{\mathrm{a})}$ & $2.2 \pm 1.4^{\mathrm{a})}$ & 0.430 \\
\hline \multicolumn{4}{|l|}{ C1-C2 angle $\left({ }^{\circ}\right)$} \\
\hline Preoperative & $20.0 \pm 9.8$ & $17.6 \pm 9.3$ & 0.587 \\
\hline Postoperative & $25.1 \pm 7.8^{\text {a) }}$ & $25.2 \pm 8.0^{\mathrm{a})}$ & 0.974 \\
\hline Follow-up & $24.6 \pm 8.0^{\mathrm{a})}$ & $24.4 \pm 8.6^{\text {a) }}$ & 0.968 \\
\hline Fusion rate & $10^{b} / 10(100 \%)$ & $9^{\text {b) }} / 9(100 \%)$ & 1.000 \\
\hline
\end{tabular}

Values are presented as mean \pm standard deviation or number of patients. No significant differences in any parameters were seen between groups. PS, pedicle screwing; LS, laminar screwing.

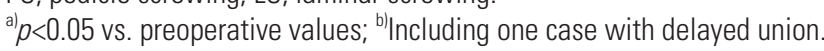

be applied to all patients, due to anatomical variations in the C2 lamina. A cadaveric study by Cassinelli et al. [19] showed that $70.6 \%$ of specimens had a laminar thickness of C2 $\geq 5 \mathrm{~mm}$, and $92.6 \%$ had a thickness of $\geq 4 \mathrm{~mm}$, with a wide range of laminar thickness noted (range, 1.35-9.77 $\mathrm{mm})$. These data indicated that one unilateral C2LS with a diameter of $3.5 \mathrm{~mm}$ could be used for $92.6 \%$ of patients. We thus applied a hybrid of unilateral C2PS and contralateral C2LS when bilateral C2PS could not be introduced due to a small pedicle and/or asymmetry of the VAs.

This study showed that clinical and radiological outcomes of unilateral C2PS and contralateral C2LS were comparable to those of bilateral C2PS for C1-C2 posterior fixation. No significant differences were seen in reduction of neck pain post-surgery, improvement of neurological status evaluated with JOA score, restoration of $\mathrm{C} 1-\mathrm{C} 2$ alignment, and final fusion rate. However, one case in the unilateral C2PS+LS group showed C2 spinous process fracture immediately after surgery. There is a possibility that C2LS can weaken the C2 spinous process and induce fracture. This case involved a patient with achondroplasia and a small C2 lamina. In such cases, decortications to C2 lamina and spinous process should be performed more gently and carefully, and more stabilized 
cervical orthosis might be considered postoperatively.

A case from the bilateral C2PS group with postoperative fracture of the $\mathrm{C} 1$ anterior arch also provided an important suggestion for instrumentation technique. The patient with retro-odontoid pseudotumor was an old blind man who was prone to falls, and he underwent $\mathrm{C} 1$ laminectomy combined with $\mathrm{C} 1-\mathrm{C} 2$ posterior fixation. Spontaneous resorption of the pseudotumor after $\mathrm{C} 1-\mathrm{C} 2$ fixation is a well-known phenomenon. However, this case required $\mathrm{C} 1$ laminectomy, because of acute and progressive myelopathy. Although the C1LMS-C2PS method is considered to offer the most rigid fixation technique for atlantoaxial lesions, C1 laminectomy inevitably weakens the stability of the $\mathrm{C} 1-\mathrm{C} 2$ construct and lessens the bedarea for bone grafting. This case suggests that when $\mathrm{C} 1$ laminectomy is required, application of a rod connector to connect bilateral rods needs to be considered.

As suggested previously, C2LS should be used in the following cases: a small pedicle of the vertebral arch, into which even a screw of $3.5 \mathrm{~mm}$ in diameter cannot be inserted; cases with markedly severe osteosclerosis of the pedicle of the vertebral arch with no medullary space; treatment of the dominant side, in cases of asymmetrical VA, or the opposite side, in cases of unilateral VA occlusion; and patients with high-riding VA $[6,20]$. VA injury is directly linked to intra- or perioperative death, if the VA communicates only unilaterally to the basilar artery or has an obvious dominant side [20]. Patients with a dominant VA are thus good candidates for the C2LS technique, even if the pedicle anatomy is sufficient to insert PS [20].

\section{Conclusions}

The present study showed that the unilateral C2PS plus contralateral C2LS fixation technique and the bilateral C2PS fixation technique for $\mathrm{C} 1-\mathrm{C} 2$ posterior fixation had comparable clinical and radiological results. The C2LS technique is considered safer than the C2PS technique, but C2 spinous process fracture may occur as a postoperative complication.

\section{Conflict of Interest}

No potential conflict of interest relevant to this article was reported.

\section{References}

1. Goel A, Laheri V. Plate and screw fixation for atlantoaxial subluxation. Acta Neurochir (Wien) 1994;129: 47-53.

2. Harms J, Melcher RP. Posterior C1-C2 fusion with polyaxial screw and rod fixation. Spine (Phila $\mathrm{Pa}$ 1976) 2001;26:2467-71.

3. Park JS, Cho DC, Sung JK. Feasibility of C2 translaminar screw as an alternative or salvage of C2 pedicle screws in atlantoaxial instability. J Spinal Disord Tech 2012;25:254-8.

4. Vergara P, Bal JS, Hickman Casey AT, Crockard HA, Choi D. C1-C2 posterior fixation: are 4 screws better than 2? Neurosurgery 2012;71:86-95.

5. Wright NM. Posterior C2 fixation using bilateral, crossing C2 laminar screws: case series and technical note. J Spinal Disord Tech 2004;17:158-62.

6. Ma W, Feng L, Xu R, et al. Clinical application of C2 laminar screw technique. Eur Spine J 2010;19:1312-7.

7. Claybrooks R, Kayanja M, Milks R, Benzel E. Atlantoaxial fusion: a biomechanical analysis of two C1C2 fusion techniques. Spine J 2007;7:682-8.

8. Dmitriev AE, Lehman RA Jr, Helgeson MD, Sasso RC, Kuhns C, Riew DK. Acute and long-term stability of atlantoaxial fixation methods: a biomechanical comparison of pars, pedicle, and intralaminar fixation in an intact and odontoid fracture model. Spine (Phila Pa 1976) 2009;34:365-70.

9. Yuan F, Yang HL, Guo KJ, et al. A clinical morphologic study of the C2 pedicle and isthmus. Eur Spine J 2013;22:39-45.

10. Tan M, Wang H, Wang Y, et al. Morphometric evaluation of screw fixation in atlas via posterior arch and lateral mass. Spine (Phila Pa 1976) 2003;28:888-95.

11. Hong X, Dong Y, Yunbing C, Qingshui Y, Shizheng $Z$, Jingfa L. Posterior screw placement on the lateral mass of atlas: an anatomic study. Spine (Phila $\mathrm{Pa}$ 1976) 2004;29:500-3.

12. Currier BL, Todd LT, Maus TP, Fisher DR, Yaszemski MJ. Anatomic relationship of the internal carotid artery to the $\mathrm{C} 1$ vertebra: A case report of cervical reconstruction for chordoma and pilot study to assess the risk of screw fixation of the atlas. Spine (Phila Pa 1976) 2003;28:E461-7.

13. Hong JT, Lee SW, Son BC, Sung JH, Kim IS, Park CK. Hypoglossal nerve palsy after posterior screw place- 
ment on the C-1 lateral mass. Case report. J Neurosurg Spine 2006;5:83-5.

14. Ebraheim N, Rollins JR Jr, Xu R, Jackson WT. Anatomic consideration of $\mathrm{C} 2$ pedicle screw placement. Spine (Phila Pa 1976) 1996;21:691-5.

15. Miyakoshi N, Shimada Y, Hongo M. Posterior fixation for atlantoaxial instability: various surgical techniques with wire and screw fixation. In: Lewandrowski KU, editor. Spinal reconstruction: clinical examples of applied basic science, biomechanics and engineering. New York: Informa Healthcare; 2007. p.457-67.

16. Yonenobu K, Abumi K, Nagata K, Taketomi E, Ueyama K. Interobserver and intraobserver reliability of the japanese orthopaedic association scoring system for evaluation of cervical compression myelopathy. Spine (Phila Pa 1976) 2001;26:1890-4.

17. Wright NM, Lauryssen C. Vertebral artery injury in C1-2 transarticular screw fixation: results of a sur- vey of the AANS/CNS section on disorders of the spine and peripheral nerves. American Association of Neurological Surgeons/Congress of Neurological Surgeons. J Neurosurg 1998;88:634-40.

18. Yoshida M, Neo M, Fujibayashi S, Nakamura T. Comparison of the anatomical risk for vertebral artery injury associated with the C2-pedicle screw and atlantoaxial transarticular screw. Spine (Phila Pa 1976) 2006;31:E513-7.

19. Cassinelli EH, Lee M, Skalak A, Ahn NU, Wright NM. Anatomic considerations for the placement of C2 laminar screws. Spine (Phila Pa 1976) 2006;31: 2767-71.

20. Matsubara T, Mizutani J, Fukuoka M, Hatoh T, Kojima $\mathrm{H}$, Otsuka T. Safe atlantoaxial fixation using a laminar screw (intralaminar screw) in a patient with unilateral occlusion of vertebral artery: case report. Spine (Phila Pa 1976) 2007;32:E30-3. 